OAK RIDGE NATIONAL LABORATORY

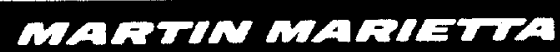

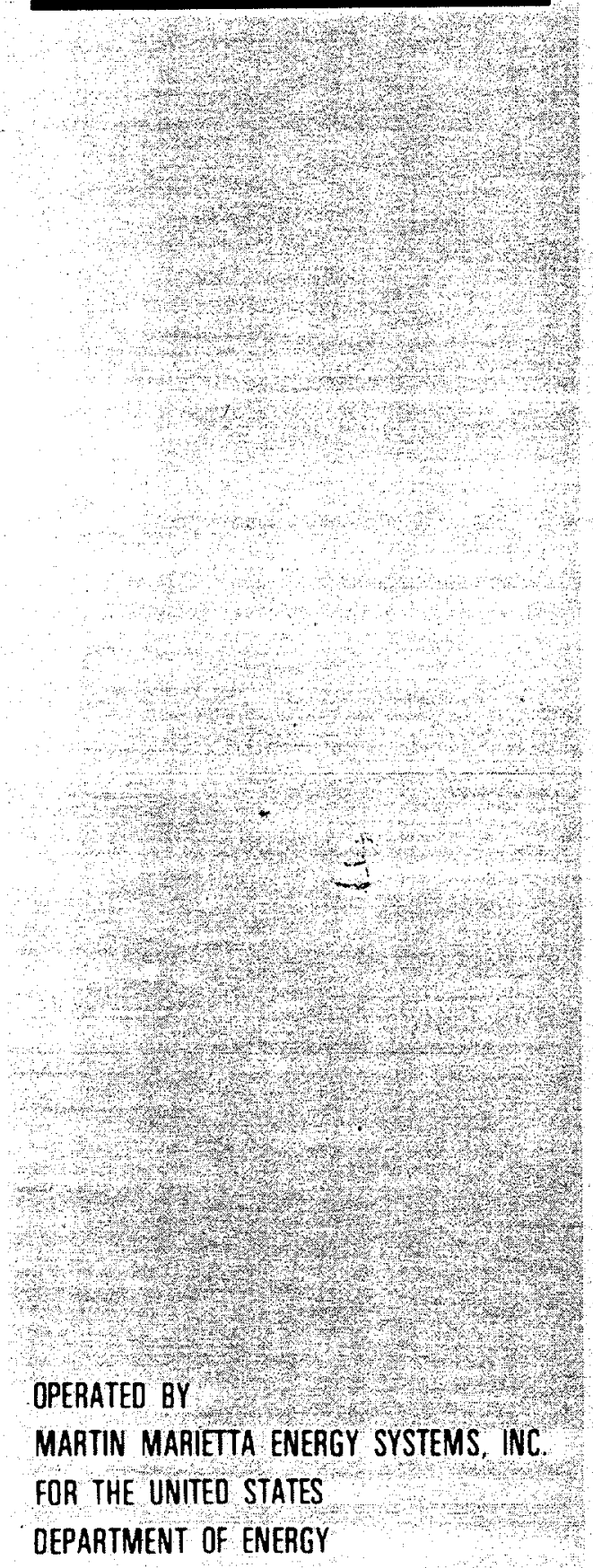

\section{Laser Range Camera Modeling}

\author{
Kai Storjohann
}


This report has been reproduced directly from the best available copy.

Available to DOE and DOE contractors from the Office of Scientific and Technical Information, P.O. Box 62, Oak Ridge, TN 37831; prices available from (615) 576-8401, FTS 626-8401.

Available to the public from the National Technical Information Service, U.S. Department of Commerce, 5285 Port Royal Rd., Springfield, VA 22161.

NTIS price codes-Printed Copy: AO2 Microfiche AO1

This report was prepared as an account of work sponsored by an agency of the United States Government. Neither the United States Government nor any agency thereof, nor any of their employees, makes any warranty, express or implied, or assumes any legal liability or responsibility for the accuracy, completeness, or usefulness of any information, apparatus, product, or process disclosed, or represents that its use would not infringe privately owned rights. Reference herein to any specific commercial product, process, or service by trade name, trademark, manufacturer, or otherwise, does not necessarily constitute or imply its endorsement, recommendation, or favoring by the United States Government or any agency thereof. The views and opinions of authors expressed herein do not necessarily state or reflect those of the United States Government or any agency thereof. 
Engineering Physics and Mathematics Division

Laser Range Camera Modeling

Kai Storjohann

DATE PUBLISHED - April 1990

Prepared by the

OAK RIDGE NATIONAL LABORATORY

Oak Ridge, Tennessee 37831

operated by

MARTIN MARIETTA ENERGY SYSTEMS, INC.

for the

U.S. DEPARTMENT OF ENERGY

under contract DE-AC05-84OR21400 


\section{CONTENTS}

ABSTRACT . . . . . . . . . . . . . . . . . . . $\mathrm{v}$

1. INTRODUCTION

2. THE LASER RANGE CAMERA MODEL AND INTRINSIC

PARAMETERS $\cdot \cdot \cdot \cdot \cdot \cdot \cdot \cdot \cdot \cdot \cdot \cdot \cdot \cdot \cdot \cdot \cdot 3$

3. TRANSFORMATION OF THE LASER RANGE CAMERA MODEL INTO A STANDARD CAMERA PINHOLE MODEL . . . . . . . . . 7

4. SUMMARY . . . . . . . . . . . . . . . . . . . . . 9

REFERENCES . . . . . . . . . . . . . . . . . . 11 


\section{LIST OF FIGURES}

Fig

$\underline{\text { Page }}$

1 Grid imaged by a SC with a wide-angle lens $\quad$. . . . . . . . 1

2 Grid imaged by the LRC . . . . . . . . . . . . . 2

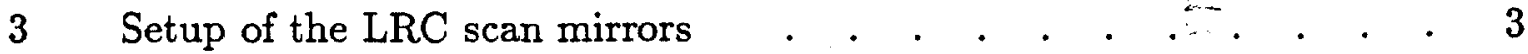

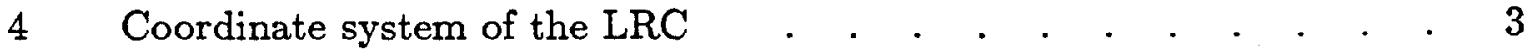

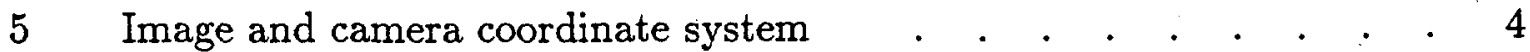

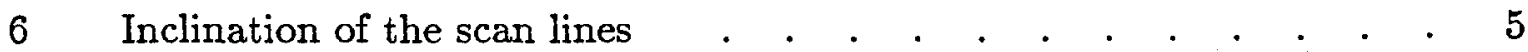

$7 \quad$ Intersection of the laser beam with a virtual image plane $\quad . \quad$. $\quad 7$ 


\begin{abstract}
This paper describes an imaging model that was derived for use with a laser range camera (LRC) developed by the Advanced Intelligent Machines Division of Odetics. ${ }^{1}$ However, this model could be applied to any comparable imaging system. Both the derivation of the model and the determination of the LRC's intrinsic parameters are explained. For the purpose of evaluating the LRC's extrinsic parameters, i.e., its external orientation, a transformation of the LRC's imaging model into a standard camera's (SC) pinhole model is derived. By virtue of this transformation, the evaluation of the LRC's external orientation can be found by applying any $\mathrm{SC}$ calibration technique.
\end{abstract}




\section{INTRODUCTION}

LRC's arc attractive sensor systems for the purpose of 3-D machine vision tasks because they acquire dense range (and reflectance) images. These range images contain the coordinates of surfaces with respect to the sensor's (internal) coordinate system. If such a sensor system is designated for world modeling; e.g., for navigation or manipulation tasks, the transformation of the sensor data into a world coordinate system is necessary, and requires the calibration of the sensor system. The process of camera calibration consists of determining the camera's imaging model, intrinsic parameters, and rotation and translation (extrinsic parameters) with respect to a world coordinate system.

When first comparing the LRC's reflectance image with the illumination images of SCs, the image generating process seems to be similar. This might lead to the conclusion that the application of SC calibration techniques for the LRC is sufficient. However, the different distortions of a grid imaged by a SC (Fig. 1) and by a LRC (Fig. 2) reveal differences in the imaging processes between the two cameras.

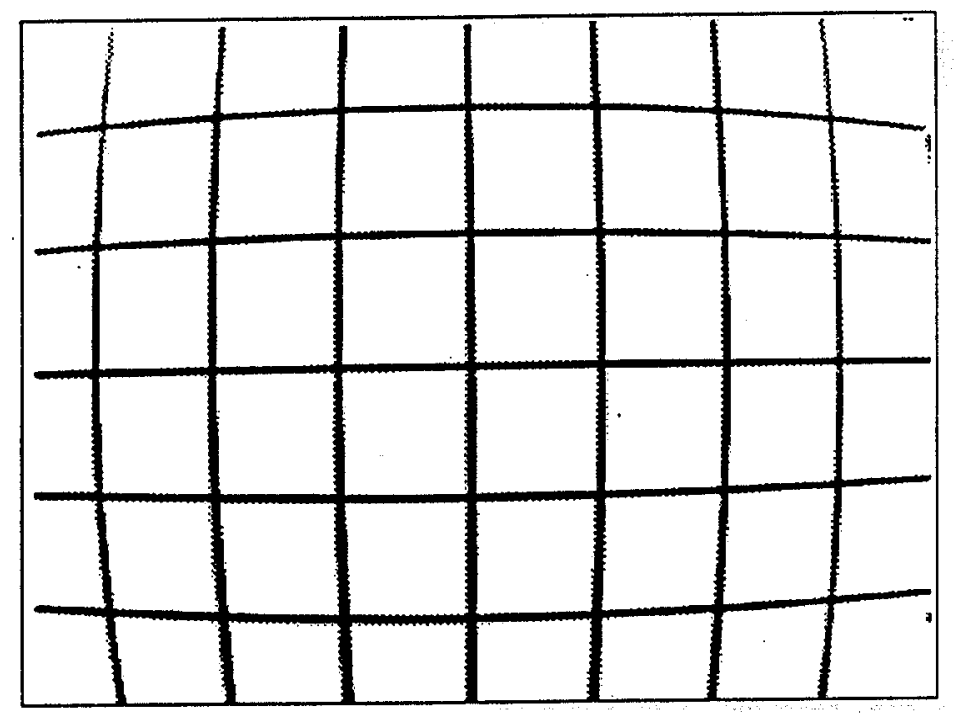

Fig. 1. Grid imaged by a SC with a wide-angle lens.

Unlike the radial distortion of SCs images*:2

$$
\begin{aligned}
X_{S C} & =f_{S C}\left(X_{g r i d}^{2}+Y_{g r i d}^{2}\right) \cdot X_{g r i d} \\
Y_{S C} & =f_{S C}\left(X_{g r i d}^{2}+Y_{g r i d}^{2}\right) \cdot Y_{g r i d}
\end{aligned}
$$

* Center of the coordinate systems is in the middle of Fig. 1 
the distortion of the LRC's image can be modeled as follows:*

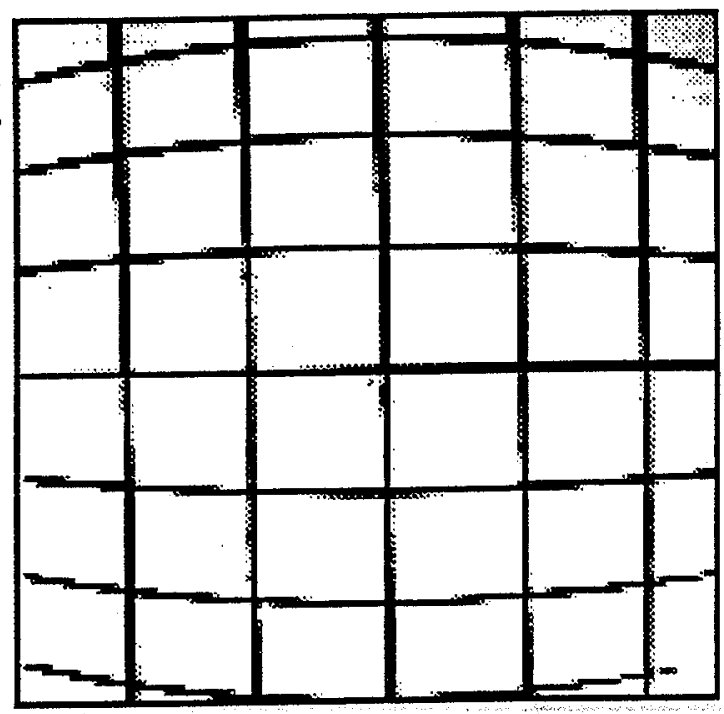

Fig. 2. Grid imaged by the LRC.

$$
\begin{aligned}
X_{L R C} & =X_{g r i d} \\
Y_{L R C} & =f_{L R C}\left(X_{g r i d}\right) \cdot Y_{g r i d}
\end{aligned}
$$

For high accuracy LRC calibration, any approach has to take into consideration the specific imaging process of the LRC.

The organization of the paper is as follows. In Section 2, the LRC's imaging model is derived and the intrinsic parameters are determined. In Section 3 , the transformation of the LRC's imaging model onto the SC pinhole model is presented. The paper concludes with a summary and prospects for future work.

* Center of the coordinate systems is in the middle of Fig. 2. 


\section{THE LASER RANGE CAMERA MODEL AND INTRINSIC PARAMETERS}

The Odetics LRC $^{1}$ transmits an amplitude modulated laser. beam. The power of the returned signal is a function of the target reflectance, and the phase shift is a function of the round trip travel time, i.e., target range. While scanning the laser beam horizontally and vertically, the range and reflectance data are spatially registered in range and reflectance images.

The scan mechanism consists of a rotating polygon mirror for the horizontal deflection, and a planar mirror, rotating up and down, for the vertical deflection of the laser beam (Fig. 3). Depending on the attitude of the scan mirrors, the angles of the deflected beam are $\alpha_{v}$ and $\alpha_{h}$ (Fig. 4).

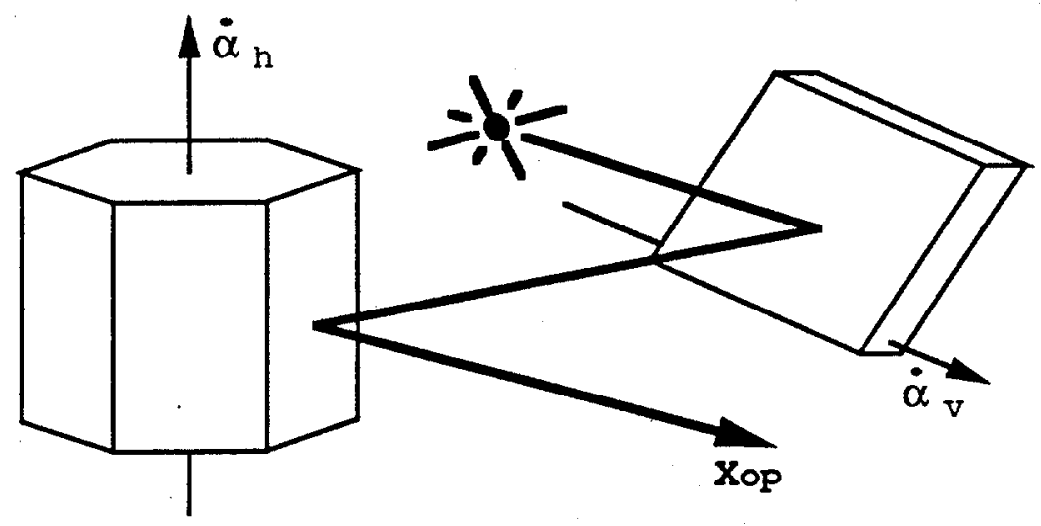

Fig. 3. Setup of the LRC scan mirrors.

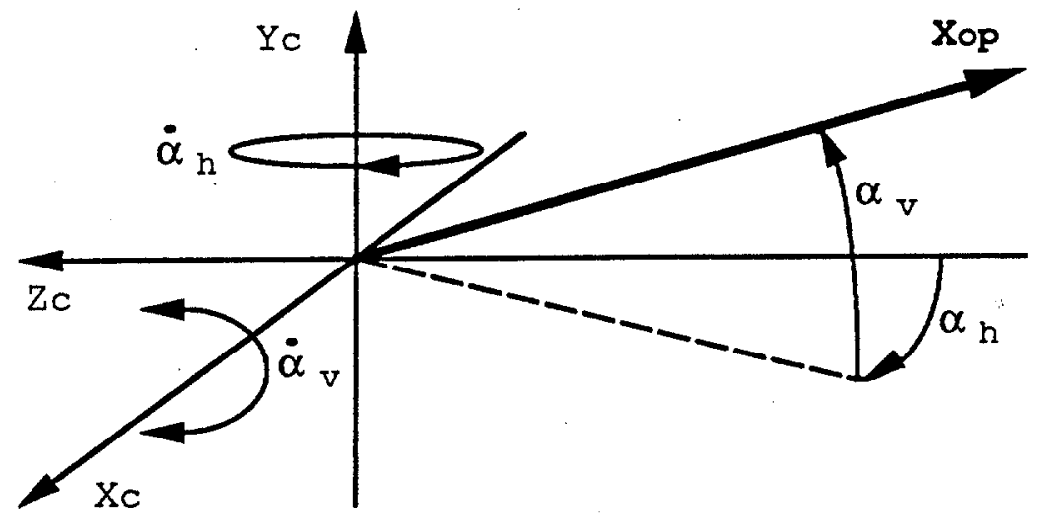

Fig. 4. Coordinate system of the LRC. 
The horizontal scan mirror is rotating with a constant angle velocity of $\dot{\alpha}_{v m}$; the rotation of the vertical scan mirror $\dot{\alpha}_{v m}$ is governed by a rotating cam driven by the horizontal scan mirror. The horizontal and vertical angle velocities of the deflected beam are $\dot{\alpha}_{h}=2 \dot{\alpha}_{h m}$ and $\dot{\alpha}_{v}=2 \dot{\alpha}_{v m}$.

While the beam is scanning, reflectance and depth data are registered. The sample time for a single pixel is $t_{s p}$; the sample time for an entire scan line, including horizontal retrace is $t_{s l}$. The spread angles of two consecutive horizontal pixels and two consecutive scan lines are $\dot{\alpha}_{v} t_{s p}$ and $\dot{\alpha}_{h} t_{s l}$, respectively. $\dot{\alpha}_{h m}, \dot{\alpha}_{v m}, t_{s p}, t_{s l}$ are intrinsic camera parameters. Their values can be taken from the LRC manual. ${ }^{1}$

The camera coordinates of an imaged object point $\mathbf{X}_{\text {op }}$ are expressed by spherical coordinates $a_{h}, a_{v}, r$. The spherical coordinates $a_{v}, a_{h}$ are equal to the angles of the deflected laser beam. The length of the vector $\mathbf{X}_{\text {op }}$ equals the measured range (Fig. 4).

The image coordinates $r$ and $c$ correspond to the row and column number of image pixels (Fig. 5). The translation of the camera with respect to the image coordinate system is determined by $r_{m}$ and $c_{m}$, and can be placed in the center of the LRC image. An accurate estimation of $r_{m}$ and $c_{m}$ can be achieved by applying the experimental techniques for SCs proposed by Lenz. ${ }^{3}$

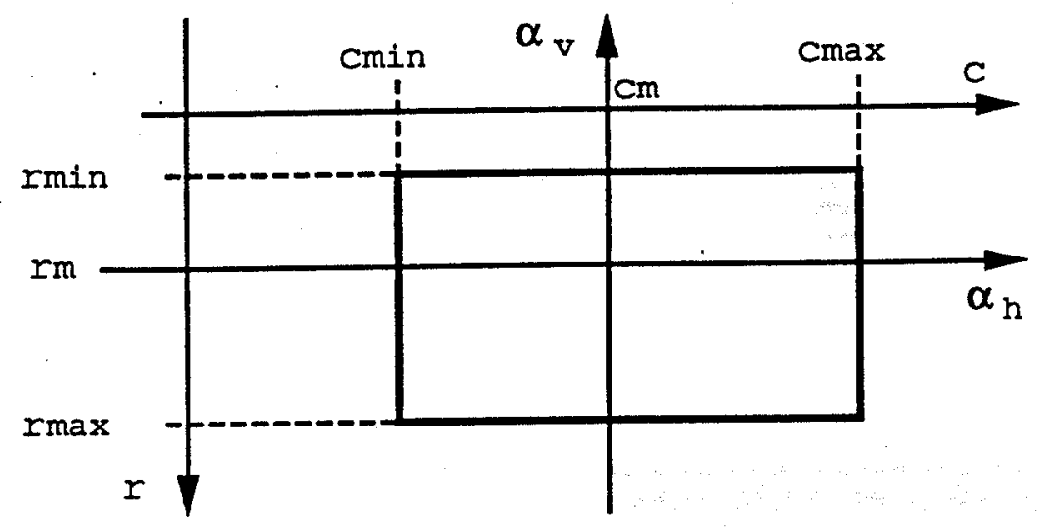

Fig. 5. Image and camera coordinate system.

Once the intrinsic parameters are known, the mapping equations of the camera coordinates into the image coordinates of the range $(D(r, c))$ or reflectance images $(R(r, c))$ can be determined. The measured range value $(D(r, c))$ depends linearly on the target distance. ${ }^{1}$ The measured reflectance value $(R(r, c))$ is a function of the target surface albedo and orientation.

If the vertical scan mirror is not moving within a scan line, the mapping of image coordinates onto camera coordinates is given by the following equations: 


$$
\begin{aligned}
& \alpha_{h}(c)=\dot{\alpha}_{h} t_{s p}\left(c-c_{m}\right) \\
& \alpha_{v}(r)=\dot{\alpha}_{v} t_{s l}\left(r_{m}-r\right)
\end{aligned}
$$

Because of the coupling between the vertical scan mirror and the horizontal scan mirror due to the cam, the scan lines arc inclined. The vertical scan mirror is moving within each scan line (Fig. 6) and an offset, depending on the horizontal beam angle, has to be added:

$$
\Delta \alpha_{v}\left(\alpha_{h}\right)= \pm \alpha_{h} \frac{\dot{\alpha}_{v}}{\dot{\alpha}_{h}}
$$

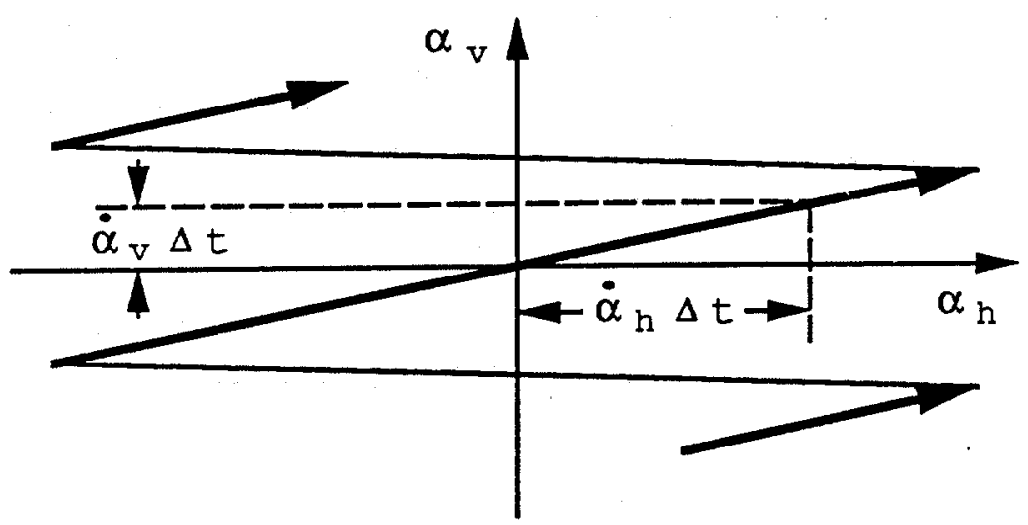

Fig. 6. Inclination of the scan lines.

When the vertical scan mirror is moving up or down the sign in Eq. (5) is positive or negative, respectively. Combining Eq. (4) and Eq. (5) leads to the final transformation equations:

$$
\begin{aligned}
\alpha_{h}(c) & =\dot{\alpha}_{h} t_{s p}\left(c-c_{m}\right) \\
\alpha_{v}(r, c) & =\dot{\alpha}_{v} t_{s l}\left(r_{m}-r\right) \pm \alpha_{h} \frac{\dot{\alpha}_{v}}{\dot{\alpha}_{h}} \\
& =\dot{\alpha}_{v} t_{s l}\left(r_{m}-r\right) \pm \dot{\alpha}_{v} t_{s p}\left(c-c_{m}\right)
\end{aligned}
$$

The inversion of Eq. (6) and Eq. (7) defines the transformation of camera into image coordinates: 


$$
\begin{aligned}
c\left(\alpha_{h}\right) & =r n d\left(c_{m}+\frac{\alpha_{h}}{\dot{\alpha}_{h} t_{s p}}\right) \\
r\left(\alpha_{v}, \alpha_{h}\right) & =r n d\left(r_{m}-\frac{1}{\dot{\alpha}_{v} t_{s l}}\left(\alpha_{v} \mp \dot{\alpha}_{v} t_{s p}\left(c-c_{m}\right)\right)\right) \\
& =r n d\left(r_{m}-\frac{1}{\dot{\alpha}_{v} t_{s l}}\left(\alpha_{v} \mp \alpha_{h} \frac{\dot{\alpha}_{v}}{\dot{\alpha}_{h}}\right)\right)
\end{aligned}
$$

Equations (6), (7), (8), and (9) express the relationship between the horizontal and vertical beam angles (spherical camera coordinates) and the image coordinates. 


\section{TRANSFORMATION OF THE LASER RANGE CAMERA MODEL INTO A STANDARD CAMERA PINHOLE MODEL}

Once the imaging model and its intrinsic parameters are known, the extrinsic parameters remain to be determined. They define the camera's rotation and translation with respect to a world coordinate system and are also referred to as the external camera orientation. Several calibration techniques for SCs have been reported..$^{4-7}$ Therefore, it is convenient to simply derive a transformation from the LRC imaging model onto the SC pinhole model. By virtue of such a transformation, any of the SC calibration techniques can be utilized for the evaliuation of the LRC external orientation.

Equation 10 shows the parametric equation of the laser beam in cartesian coordinates as a function of its spherical coordinates.

$$
\lambda\left(\begin{array}{c}
X_{c} \\
Y_{c} \\
Z_{c}
\end{array}\right)=\lambda\left(\begin{array}{c}
\sin \alpha_{h} \cos \alpha_{v} \\
\sin \alpha_{v} \\
-\cos \alpha_{h} \cos \alpha_{v}
\end{array}\right)
$$

At this point, a virtual image plane is introduced (Fig. 7). The $\mathrm{X}$ and $\mathrm{Y}$ axes of the virtual image plane coordinate system, $X_{p}$ and $Y_{p}$, are parallel to the $\mathrm{X}$ and $\mathrm{Y}$ axes of the LRC coordinate system.

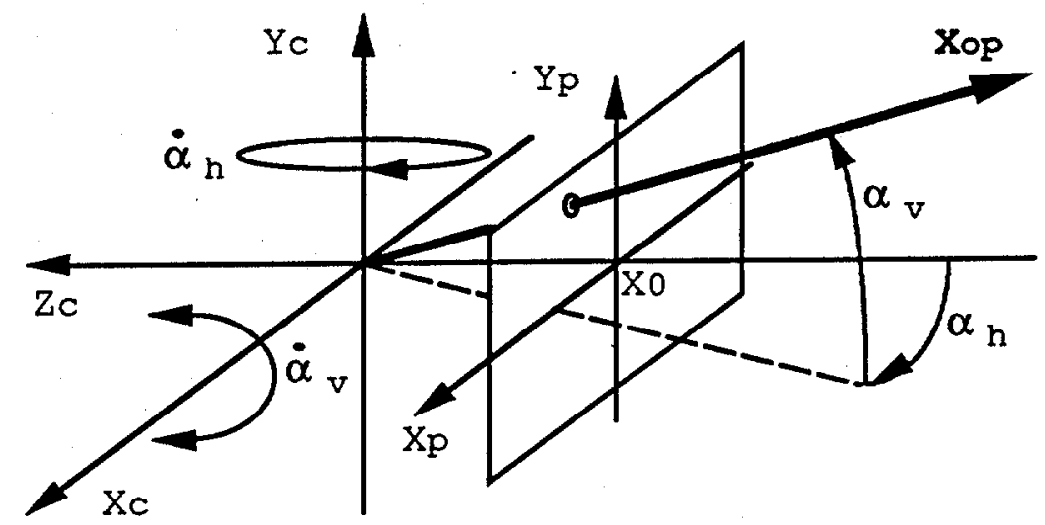

Fig. 7. Intersection of the laser beam with a virtual image plane.

$Z_{0}$ corresponds to the $\mathrm{SC}$ focal length. It can be chosen arbitrarily because it merely determines the scaling on the virtual image plane. For the following calculations $Z_{0}=-1$. The intersection of the laser beam with the virtual image plane is given by: 


$$
X_{p}\left(\alpha_{h}\right)=\frac{\sin \alpha_{h} \cos \alpha_{v}}{\cos \alpha_{h} \cos \alpha_{v}}=\tan \alpha_{h}
$$

and

$$
Y_{p}\left(\alpha_{v}, \alpha_{h}\right)=\frac{\sin \alpha_{v}}{\cos \alpha_{h} \cos \alpha_{v}}=\frac{1}{\cos \alpha_{h}} \tan \alpha_{h}
$$

Since $X_{p}$ is a function of $a_{v}$ only, Eqs. (11) and (12) can be easily inverted:

$$
\begin{aligned}
\alpha_{h}\left(X_{p}\right) & =\arctan \left(X_{p}\right) \\
\alpha_{v}\left(X_{p}, Y_{p}\right) & =\arctan \left(Y_{p} \cos \left(\arctan \left(X_{p}\right)\right)\right)
\end{aligned}
$$

Eqs. (11) and (12) describe the mapping of the LRC imaging model into a SC pinhole model. Eqs. (13) and (14) describe the inverse mapping. 


\section{SUMMARY}

With Eqs. (6), (7), (11) and (12), the image coordinates $r$ and $c$ can be mapped into the coordinates of a virtual image plane. By virtue of this transformation, the calibration of the LRC external orientation can be evaluated with calibration techniques for SCs. At the moment, experimental results are being generated by applying the calibration technique published by Lenz. ${ }^{7}$ These experiments reveal promising calibration results and the objective of future work will include an accurate determination of the calibration errors. 


\section{REFERENCES}

1. 3-D Laser Imaging System User's Guide, Odetics, Anaheim, CA (1990).

2. R. Y. Tsai, "An Efficient and Accurate Camera Calibration Technique for 3D Machine Vision," in Proc. of IEEE Int'l. Conf. on Robotics and Automation, San Francisco, CA, pp. 364-374 (April 1986).

3. R. K. Lenz and R. Y. Tsai, "Techniques for Calibration of the Scale Factor and Image Center for High Accuracy 3-D Machine Vision Metrology," IEEE Trans. Patt. Anal. Mach. Intell., Vol. PAMI-10, No. 5, pp. 713-720 (1988).

4. Malhotra, "A Computer Program for the Calibration of Close-Range Cameras, Proceedings of Symposium on Close Range Photogrammetric Systems, Urbana, IL (1971).

5. I. Sobel, "On Calibrating Computing Controlled Cameras for Perceiving 3-D Scenes," Artificial Intelligence, 5, pp. 185-198 (1974).

6. R. Y. Tsai, "A Versatile Camera Calibration Technique for High Accuracy 3-D Machine Vision Metrology using Off-the-Shelf TV Cameras and Lenses," IBM Research Report RC 51342 (1985).

7. R. K. Lenz, "Linsenfehlerkorrigierte Eichung von Halbleiterkameras mit Standardobjektiven für hochgenaue 3D-Messungen in Echtzeit," 9 DAGM Symposium, Braunschweig, FRG, E. Paulus (Ed.), Springer Verlag (1987). 


\section{INTERNAL DISTRIBUTION}

1. B. R. Appleton

2. J. E. Baker

3. M. Beckerman

4. C. W. Glover

5. J. P. Jones

6-10. H. E. Knee

11. G. E. Liepins

12. F. C. Maienschein

13-17. R. C. Mann

18-22. E. M. Oblow

23. F. G. Pin

24. D. B. Reister

25-29. K. Storjohann

30-34. F. J. Sweeney

35. M. A. Unseren
36. J. J. Dorning (consultant)

37. R. M. Haralick (consultant)

38. J. E. Leiss (consultant)

39. M. F. Wheeler (consultant)

40. N. Moray (consultant)

41. EPMD Reports Office

42-43. Laboratory Records Department

44. Laboratory Records, ORNL-RC

45. Document Reference Section

46. Central Research Library

47. ORNL Patent Section

\section{EXTERNAL DISTRIBUTION}

48. P. Allen, Department of Computer Science, 450 Computer Science Columbia University, New York, New York 10027

49. H. Alter, MS-542, Division of Advanced Technology Development, 19901 Germantown Road, U.S. Department of Energy, Washington, DC 20545

50. W. Book, Department of Mechanical Engineering, J. S. Coon Building, Room 306, Cherry Street, Georgia Institute of Technology, Atlanta, GA 30332

51. S. Dubowsky, Building 3 - Room 469A, Massachusetts Institute of Technology, 77 Massachusetts Avenue, Cambridge, MA 02139

52. A. Kak, Department of Electrical Engineering, Purdue University, Northwestern Avenue - Engineering Mall, Lafayette, IN 47907

53. O. Manley, DOE Headquarters - ER-15, Division of Engineering and Geosciences, Office of Basic Energy Sciences, Germantown, MD 20545

54. W. von Seelen, Ruhr Universität Bochum, Institut für Neuroinformatik, Universitätsstr 150, 4630 Bochum-1, West Germany

55. W. Snyder, Centcr for Communications and Signal Processing, North Carolina State University - Box 7914, Raleigh, NC 27695-7914

56. Office of Assistant Manager, Energy Rescarch and Development, Oak Ridge Operations Office, US/DOE, P.O. Box 2001, Oak Ridge, TN 37831

57-66. Office of Scientific and Technical Information, US/DOE, Oak Ridge, TN 37831 